\title{
Effect of Airfoil Concavity on Wind Turbine Blade Performances
}

\author{
Jianlong Ma $\left(\mathbb{D},{ }^{1}\right.$ Yafan Duan, ${ }^{1}$ Ming Zhao $\mathbb{D},{ }^{2}$ Wenchun Lv, ${ }^{1,3}$ Jianwen Wang, \\ Qilao Meng Ke, ${ }^{1}$ and Yongfeng Ren ${ }^{1}$ \\ ${ }^{1}$ School of Energy and Power Engineering, Inner Mongolia University of Technology, Hohhot 010051, China \\ ${ }^{2}$ School of Mechanical Engineering, Tianjin University, Tianjin 300072, China \\ ${ }^{3}$ Technology and Vocational Education Research Center, Inner Mongolia Technical College of Mechanics and Electrics, \\ Hohhot 010070, China \\ Correspondence should be addressed to Ming Zhao; ming.zhao@tju.edu.cn
}

Received 27 March 2019; Accepted 7 July 2019; Published 22 July 2019

Academic Editor: Francesco S. Marulo

Copyright (c) 2019 Jianlong Ma et al. This is an open access article distributed under the Creative Commons Attribution License, which permits unrestricted use, distribution, and reproduction in any medium, provided the original work is properly cited.

\begin{abstract}
Although the optimization of wind turbine blade aerodynamic performance has achieved fruitful results, whether airfoil concavity, an important method for preventing flow separation, is also feasible for improving the aerodynamic performance has not been confirmed scientifically. Thus, we selected the blade of a small horizontal-axis wind turbine as a research model and proposed an optimization method based on airfoil concavity near the trailing edge of the blade suction surface. The experimental results showed that airfoil concavity improved blade aerodynamic performance by $3-15 \%$. Subsequently, its effects on the sound pressure level within the wake flow field were investigated using an acoustic array, and the results suggested that the sound pressure level was reduced by $9.6-15.8 \%$. Lastly, a modal test of the rotor blade was conducted. Although the natural frequencies of the 1st and 2nd order vibrations had hardly changed, their vibrational stiffness were increased by 7 and $4.9 \%$, respectively, which indicated that airfoil concavity significantly improved structural robustness.
\end{abstract}

\section{Introduction}

An airfoil is the foundation of wind turbine blade design, and accordingly, optimizing its design plays a key role in improving aerodynamic performance, noise control, and structural robustness of a rotor blade. Throughout the 40year history of wind industry development, airfoil optimization has had the following three primary objectives: (1) improving blade aerodynamic performance, (2) reducing blade aerodynamic noise, and (3) increasing blade structural robustness.

In detail, blade aerodynamic performance optimization is an important issue in the development of the wind power industry. Significant advances in blade aerodynamics have considerably improved wind power technology.

In the early 1980s, with the beginning of fossil fuel depletion, the wind energy industry began to rapidly grow [1]. In its initial stages, the low aerodynamic performance of blades, which directly determines the economic benefits, was a key technical hurdle. Therefore, during this period, research focused on improving the aerodynamic performance of the blade, especially horizontal-axis wind turbine blades.

In general, aviation airfoils (such as the NACA series airfoils) were widely utilized in blade design due to their advantages of high lift coefficients and low drag coefficients, both of which significantly enhanced the early development of wind power industry. However, subsequent practices confirmed that there were a number of defects in the application of aviation airfoils in high aerodynamic performance blade design. Therefore, the industry urgently required the development of special airfoils for wind turbines. Since the mid-1980s, various specially designed airfoils have been developed, including the American $S$ series airfoil, the Dutch DU series airfoil, the Swedish FFA-W series airfoil, and the Danish Ris $\varphi$ series airfoil, which are described in detail below.

The National Renewable Energy Laboratory in the United States is one of the first organizations to specifically research wind turbine airfoils. From 1984 to 2002, they 
developed nine groups of 35 S-series airfoils [2]. Among them, seven airfoil families have thick airfoils with a relative thickness of $16-21 \%$. The other two airfoil families include thin airfoils with a relative thickness of $11-15 \%$, which are suitable for medium or small blades.

The University of Delft developed 15 wind turbine specific airfoils with a relative thickness of $15-40 \%$ [3]. The advantage of DU series airfoils over conventional aviation airfoils is that the upper airfoil is thinner and less sensitive to roughness.

The Swedish FFA-W series airfoils include the FFA-W1, FFA-W2, and FFA-W3 [4]. FFA-W1 includes six airfoils with a relative thickness of $12.8-27.1 \%$ and lift coefficient of 0.9-1.2, which are suitable for wind turbine blades with a low tip speed ratio. The FFA-W2 includes two airfoils with a relative thickness of 15.2 and $21.1 \%$, which have relatively low lift coefficients. The FFA-W3 includes seven airfoils with a relative thickness of $19.5-36 \%$, which are suitable for fixedpitch wind turbine blades.

The Danish Ris $\varphi$ airfoil series includes the $\operatorname{Ris} \varphi$-A1, $\operatorname{Ris} \varphi-\mathrm{P}$, and $\operatorname{Ris} \varphi-\mathrm{B} 1$ [5]. $\operatorname{Ris} \varphi-\mathrm{A} 1$ includes six airfoils with a relative thickness of $15-30 \%$, which are suitable for wind turbine blades above $600 \mathrm{~kW}$. Ris $\varphi$-P includes four airfoils with a relative thickness of $15,18,21$, and $24 \%$, which are suitable for wind turbine blades above $1 \mathrm{MW}$. Ris $\varphi$-B1 includes six airfoils with a relative thickness of $15-36 \%$.

At the end of the $20^{\text {th }}$ century, with the widespread utilization of small wind turbines, the development of special airfoils for small horizontal-axis wind turbine blades received increasing attention, which greatly stimulated related studies. Representative findings include IND 15045 and IND 09848 airfoils developed by Birajdar, which was designed specifically for $1 \mathrm{~kW}$ small horizontal-axis wind turbine [6]. In addition, Singh and Ahmed developed a new airfoil to solve the start-up problem [7]. Shah et al. developed an airfoil suitable for operation at low Reynolds numbers [8]. Meanwhile, Elbakheit developed an airfoil specifically for small wind turbines on buildings [9].

With the development of special airfoils for the horizontal-axis wind turbine blade, researchers have also attempted to develop optimization methods for airfoil aerodynamic performance. For example, Menon et al. performed a structural optimization of the airfoil trailing edge slotting for the NACA 64(3)-618 and DU93-W-210 airfoils and analyzed the influence of trailing edge slotting on the blade aerodynamic load [10]. Liu et al. established a parametric airfoil design method that was applied to DU93-W-210 airfoil optimization and found that this method had better convergence speed than the traditional design method [11]. Moreover, Henriques et al. applied the inverse design method to airfoil optimization [12]. Dowler and Schmitz established a solution-based stall delay model for airfoil optimization [13]. Recently, Chen et al. first proposed the general parametric representation function for airfoils based on Taylor's higherorder polynomial and applied it to airfoil design optimization [14].

However, to the authors' knowledge of the relevant literature from the past 40 years, no research has been reported that specifically aimed to improve the aerodynamic performance of wind turbine blades through airfoil concavity. Nevertheless, concavity is an important strategy for preventing flow separation that has a long history in the design of aircraft wings [15-17]. However, the flow field surrounding the wind turbine blade is more complicated than that around an aircraft wing. Whether airfoil concavity can improve aerodynamic performance of the wind turbine blade is still unknown, which is a scientific issue worthy of further study. This study aims to reveal the feasibility of the airfoil concavity technique for optimizing blade aerodynamic performance.

Since the beginning of the $21^{\text {st }}$ century, with the continued development of wind turbines, reports on environmental pollution caused by blade aerodynamic noise have emerged, gradually receiving increasing attention [18]. To this end, many countries have established market access standards and related regulations to limit wind turbine noise. Thus, aerodynamic noise control technology, which was previously neglected in blade design, has become a key technical hurdle restricting the development of the wind power industry. Recently, research on the aerodynamic noise control of wind turbine blades has achieved many valuable results, which can be divided into the following three aspects.

The first aspect is the development of specific airfoils with low aerodynamic noise. For instance, Cheng et al. developed a low-noise airfoil with a relative thickness of $21 \%$ [19]. Furthermore, the LN1 series airfoil with low aerodynamic noise was developed [20].

The second aspect is to reduce noise through airfoil structure optimization without reducing blade aerodynamic performance. Some representative studies include a method for increasing the surface roughness of blades developed by Rodrigues and Marta, which increased the output power by $8.7 \%$ and reduced the aerodynamic noise by $3.5 \mathrm{~dB}$ [21]; Benim et al. improved the aerodynamic performance of blades by $8 \%$ and reduced the sound pressure level of aerodynamic noise by $6.6 \%$ through airfoil optimization [22]; by optimizing the structure of S822 airfoil, Sanaye and Hassanzadeh increased the lift-drag ratio of blades by $26 \%$ and reduced the blade aerodynamic noise by $1.11 \%$ on average [23].

The third aspect is that noise has been reduced by sacrificing blade aerodynamic performance. For example, Bertagnolio et al. reduced blade aerodynamic noise by optimizing the airfoil suction surface design; but at the same time, the blade aerodynamic performance decreased under some conditions [24]. Through numerical simulation, Rodrigues and Marta revealed that certain degrees of power sacrifice yield significant noise reduction [25]. Despite these advances, technologies for reducing blade aerodynamic noise while maintaining blade aerodynamic performance currently require further studies.

Moreover, the structural robustness of the blade has received increasing attention in recent years [26]. Currently, most reports focus on the factors that affect a blade's structural robustness [27-29] and improvements to blade structural robustness via the installation of dampers [30, 31]. Hardly any studies have improved blade structural robustness through the airfoil structure optimization. 
This paper intends to explore the feasibility of airfoil concavity in the performance optimizations of small horizontal-axis wind turbine. Furthermore, investigation has been conducted to reveal the influence on aerodynamic performance, aerodynamic noise, and structural robustness of blades.

\section{Airfoil Concavity}

2.1. Introduction of Test System and Methods. The main reason for the improvement in blade aerodynamic performance associated with airfoil concavity is the ability to control flow separation on the airfoil surface, and the position where flow separation occurs is the optimal position for this concavity.

2.1.1. Test System and Equipment. The test system is shown schematically in Figure 1. The fluid signals were monitored by a two-dimensional high-frequency PIV, and its laser has a pulse width of $100 \mathrm{~ns}$, maximum power output of $150 \mathrm{~W}$, laser energy of $30 \mathrm{~mJ}$, and output wavelength of $527 \mathrm{~nm}$ at a trigger frequency of $1000 \mathrm{~Hz}$. The camera can continuously record 10,000 pictures per second.

The output signals of the generator (such as electric frequency, voltage, and current) were monitored by using a Fluke Norma 5000 device. The tests were completed in an open-circuit wind tunnel, which is located at the New Energy Experimental Demonstration Base in Inner Mongolia, China. The test site is shown in Figure 2.

2.1.2. Test Methods and Other Instructions. The experimental wind speed was adjusted by varying the rotational speed of the draft fan at the inlet of the wind tunnel. The blade rotational speed was adjusted by varying the access resistance of the electric load. During the test, the rotation speed of the blades was indirectly determined by dividing the generator's electrical frequency by the number of electrodes.

At the beginning of the test, the wind tunnel was opened and the frequency converter was adjusted according to the required wind speed. After the wind speed was stabilized, a synchronous trigger (8 in Figure 1) was activated by the trigger control computer (12 in Figure 1), causing the smoke generator at the inlet of the wind tunnel to continuously spray smoke containing tracer particles. When the smoke arrived at the test section, the delay triggers (9-11 in Figure 1) were triggered synchronously, and in turn, the TR-PIV and Fluke Norma 5000 systems began to operate. The sampling frequencies of the three sets of equipment were all set to $1000 \mathrm{~Hz}$, and their shooting time was $30 \mathrm{~s}$.

2.1.3. Test Results and Analysis. The selected monitoring location was the middle position on the blade suction surface. The Reynolds stress is an additional force caused by momentum exchange associated with flow field fluctuation and is an important parameter for characterizing the turbulence intensity of the flow field.

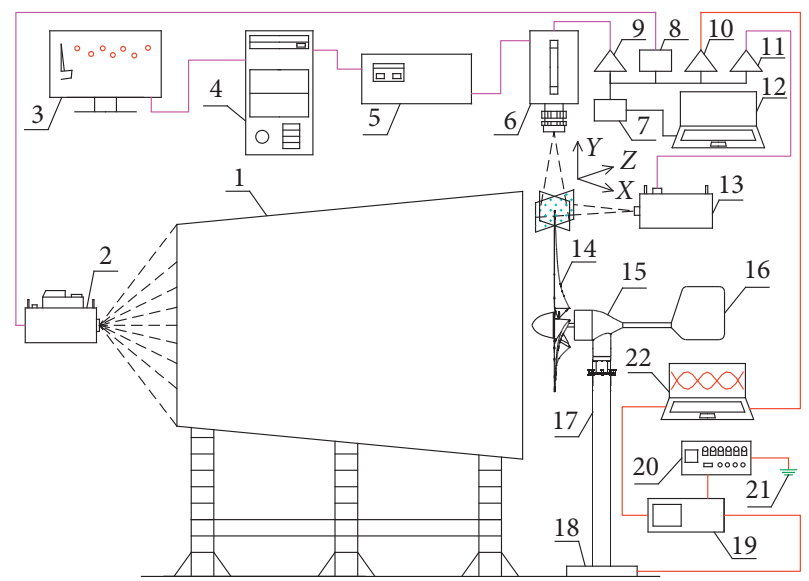

Figure 1: Test system. 1: wind tunnel; 2: smoke generator; 3: monitor; 4: computer; 5: signal collector; 6 : high-frequency camera; 7 and 8: synchronous triggers; 9-11: delay trigger; 12: master computer; 13: laser; 14: blade; 15: generator; 16: tail rudder; 17: tower; 18: base; 19: Fluke Norma 5000; 20: load; 21: ground protection; 22: computer.

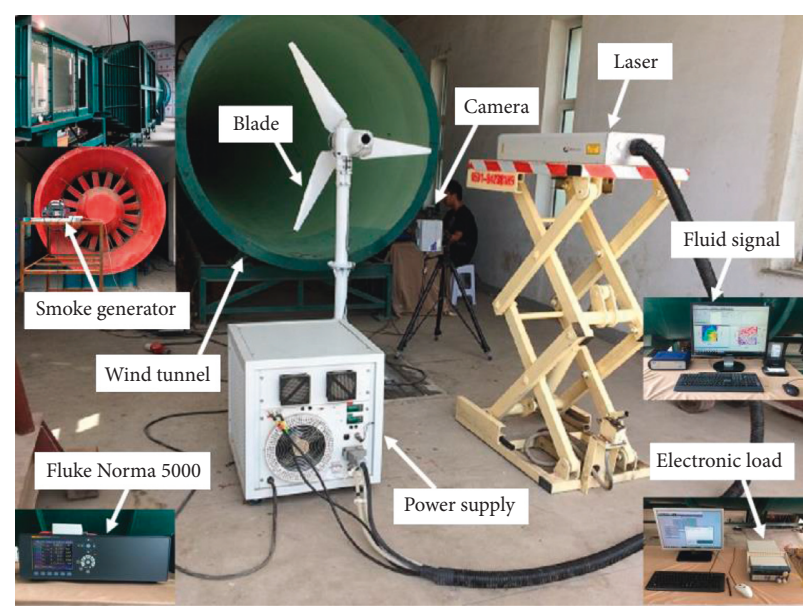

Figure 2: Test site.

As an example, at a wind speed of $8 \mathrm{~m} / \mathrm{s}$ and a tip speed ratio of 5 , we obtained the Reynolds stress at the leading edge, 0.25 -fold chord length (maximum thickness), 0.5 -fold chord length, 0.8 -fold chord length, and the trailing edge, as shown in Figure 3.

As shown in Figure 3, the Reynolds stress was more prominent at the trailing edge than at other positions because serious flow separation occurred at the trailing edge, which induced significant turbulent flow. Compared with the Reynolds stress at the leading edge, the stress at the 0.25fold and the 0.5-fold chord length was analogous, which indicates that these regions were characterized by stable flow and weak fluctuations. The Reynolds stress at the 0.8 -fold chord length was moderate, which indicates that although fluid fluctuation intensity in this region is lower than that at the trailing edge, the stress at this position shows a larger increase than that in other sections, which suggests that the flow separated near 0.8 -fold chord length. 


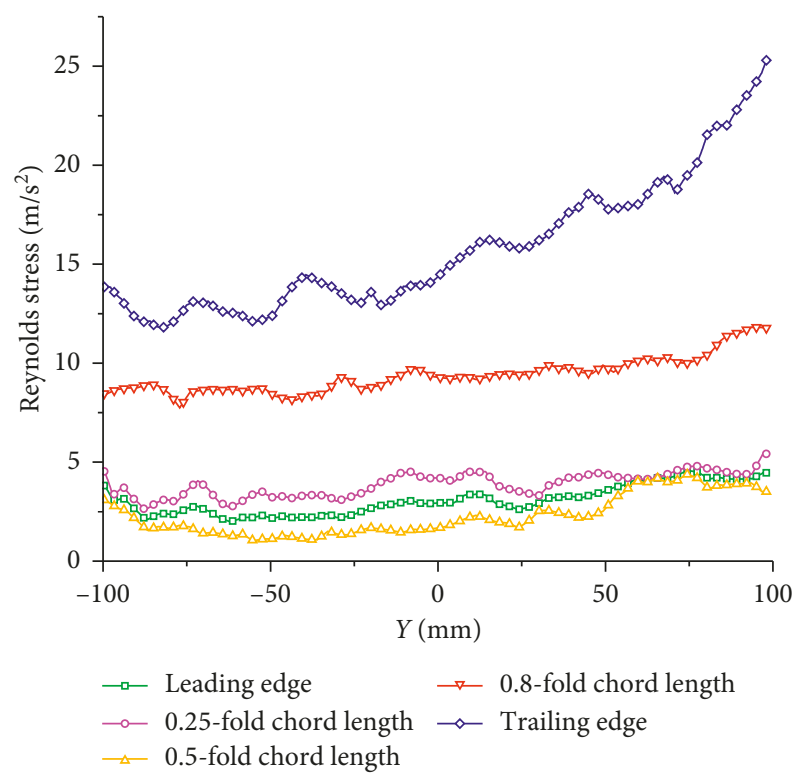

Figure 3: Reynolds stresses.

To further confirm that the fluid fluctuation was not generated by the attached flow along the suction surface of the blade at the 0.8-fold chord length in Figure 3, the $Y$ - and $Z$-directional velocity fluctuation values were extracted, as shown in Figure 4, where $y$ is the blade span direction and $z$ is the chord length direction.

If the velocity fluctuation was mainly generated by the attached flow, the intensity of the velocity fluctuation in the $Z$-direction should be significantly greater than that in the $Y$ direction. However, as shown in Figure 4, the velocity fluctuation intensity in the $Y$-direction was much larger, which suggests that the flow separated at this section.

Through the above analysis, we chose to implement the airfoil concavity at the 0.8 -fold chord length on the suction surface of the blade.

2.1.4. Analysis of Test Error and Data Reliability. The fluctuation signals of the flow field were measured by a twodimensional high-frequency PIV device developed by LaVision GmbH Company in Germany, whose measurement error is less than $1 \%$, which cannot cause a significant change in the data distribution differences in Figure 3. It has no influence on the reliability of the relevant conclusions.

2.2. Geometric Structure of Airfoil Concavity. The airfoil in Figure 5(a) is shown as an example, and the flow is assumed to separate at point $\mathrm{M}$, which was selected as the center of the airfoil concavity. Since the chord length of the airfoil was significantly larger than its maximum thickness, the airfoil concavity was elliptical.

With the center of the ellipse at point $\mathrm{M}$, the long axis $(A)$ of the ellipse was $7.2 \%$ of the chord length $(L)$, and the short axis $(B)$ was $3.6 \%$ of the chord length $(L)$. In addition, the long axis of the ellipse was tangent to the original airfoil at point $M$. In this example, the angle $(\alpha)$ between the long axis

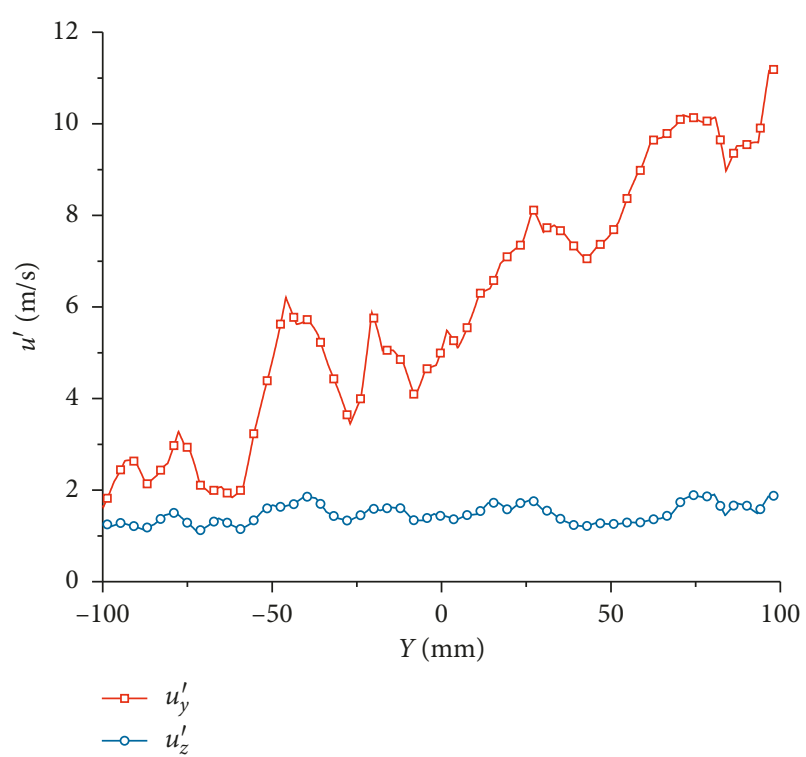

FIgURE 4: Velocity pulsations.

and the chord line was $2.25^{\circ}$. The concave and nonconcave parts were connected by a B-spline curve, as shown schematically in Figure 5(b).

2.3. Description of Blade with Concave Deformation. The original nonconcave airfoil blade has a solid structure with a length of $0.7 \mathrm{~m}$ and ten characteristic airfoil curves, as shown in Figure 6. These ten curves in the original blade were subjected to corresponding structural concave deformation, and then, the lofting of the concave airfoil curves generated the concave blade.

2.4. Determination of the Groove Length. The groove lengths were set to 350,420 , and $700 \mathrm{~mm}$ for experimental comparison. It was found that the blade output power was optimal when the groove length was $350 \mathrm{~mm}$, so a groove length of $350 \mathrm{~mm}$ was chosen for further analysis, as shown in Figure 7.

\section{Effects of Airfoil Concavity on Blade Aerodynamic Performance}

Tests were carried out at incoming wind speeds of $5-8 \mathrm{~m} / \mathrm{s}$ and blade rotation speeds of $400-650 \mathrm{r} / \mathrm{min}$, as shown in Figure $8(\mathrm{a})$, where $\omega$ represents the rotation speed of the blade. Test data for wind speeds of 5 and $6 \mathrm{~m} / \mathrm{s}$ at $650 \mathrm{r} / \mathrm{min}$ are not included because the blades could not reach these speeds via load adjustment. The experimental results show that improvements in aerodynamic performance with airfoil concavity are appreciable not only under rated conditions but also under other nonrated conditions.

To further evaluate how airfoil concavity influences blade aerodynamic performance under different conditions, we simultaneously analyzed the power increase $\left(\varphi_{P}\right)$ with exposure to identical conditions based on the following equation: 


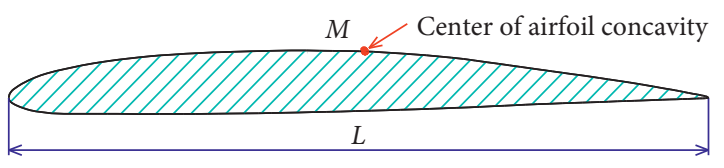

(a)

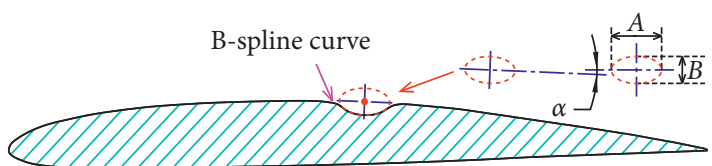

(b)

FIGURE 5: Schematic diagrams of the airfoil with and without concavity. (a) Original airfoil. (b) Airfoil with concavity.

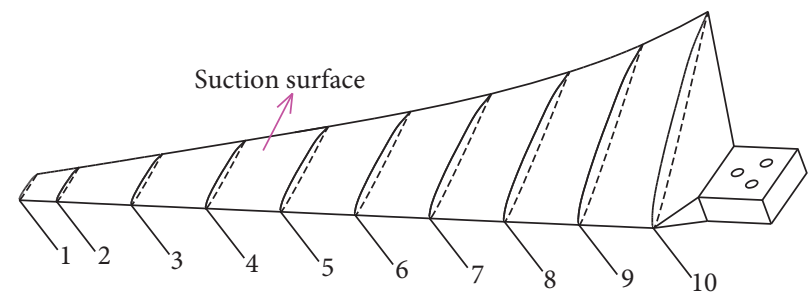

FIgURE 6: Original airfoil blade.

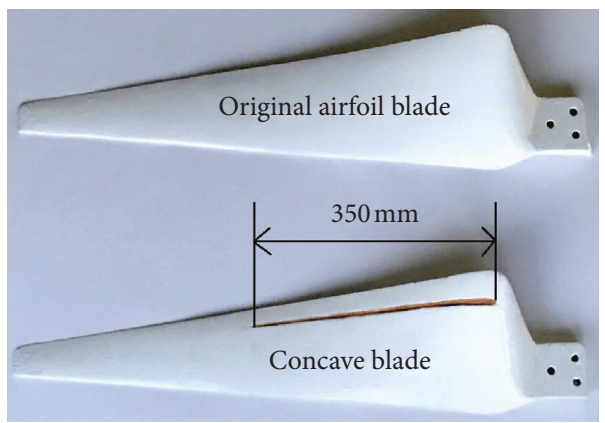

FIgURE 7: Concave blade.

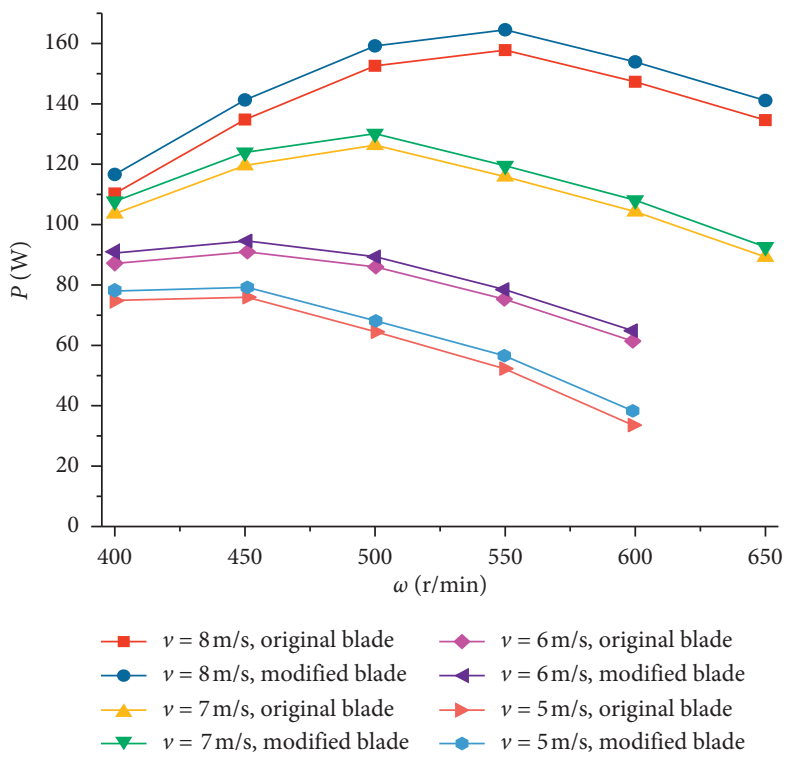

(a)

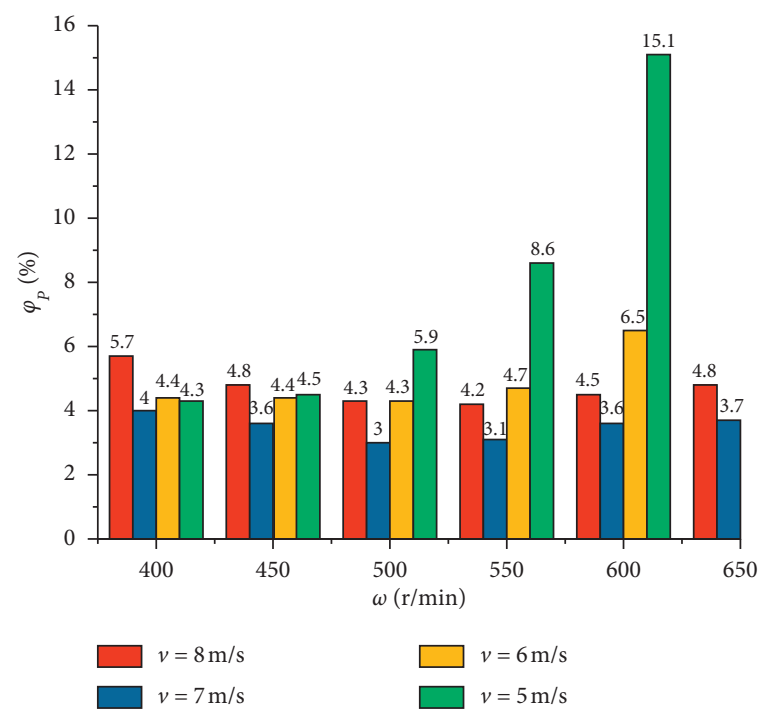

(b)

FIGURE 8: Effects of airfoil concavity on blade aerodynamic performance. (a) Difference comparison. (b) Sensitivity comparison. 


$$
\varphi_{P}=\frac{P_{2}-P_{1}}{P_{1}} \times 100 \% \text {, }
$$

where $P_{1}$ and $P_{2}$ represent the power outputs of the original and modified blades, respectively.

As shown in Figure 8(b), at a wind speed of $7 \mathrm{~m} / \mathrm{s}$, the airfoil concavity had the smallest gain in blade power output, which increased to some extent at wind speeds of 6 and $8 \mathrm{~m} / \mathrm{s}$. However, at $5 \mathrm{~m} / \mathrm{s}$, the additional power output significantly increased along with the increase in the blade rotation speed. Furthermore, at 7 and $8 \mathrm{~m} / \mathrm{s}$, increments in the blade power output due to airfoil concavity first decreased and then increased along with the increase in the blade rotation speed.

The power of the generator was measured by Fluke Norma 5000, whose measurement error is less than $0.05 \%$, which cannot cause a significant change in the data distribution differences in Figure 8. It has no influence on the reliability of the relevant conclusions.

\section{Effects of Airfoil Concavity on the Blade Aerodynamic Noise}

Sound pressure levels under different conditions are important parameters that reflect the noise pollution caused by wind turbine blades. Theoretically, the airfoil concavity should have a certain influence on blade aerodynamic noise since the flow field was greatly affected by airfoil concavity, as described above.

4.1. Test Equipment and Methods. In practice, we use a 60channel circular acoustic array developed by Brüel \& Kjær, Denmark. During testing, acoustic signals were recorded by using microphones and transmitted to the data acquisition card; they were then transmitted to the control program in the computer. Before testing, each microphone was calibrated using an acoustic calibrator, and a wind cap was installed for each microphone to prevent dust and unstable airflow from influencing the test accuracy. The acoustic array was placed $0.2 \mathrm{~m}$ behind the blades, as shown in Figure 9.

4.2. Background Noise Testing and Processing. Since background noise will interfere with the accuracy of the analysis of blade aerodynamic noise, background noise must first be tested without the wind turbine. The statistically optimized near field acoustical holography (SONAH) was used for acoustic signal analysis. For example, at a wind speed of $8 \mathrm{~m} / \mathrm{s}$, the background noise comprised the blade rotational noise $(77 \mathrm{~Hz})$ of the induced draft fan at the entrance of the wind tunnel and its harmonics noises, as shown in Figure 10.

4.3. Test Results and Analysis. Figure 11 shows the aerodynamic noise of the original and modified blades, respectively, at a wind speed of $8 \mathrm{~m} / \mathrm{s}$ and blade rotation speeds of 400,500 , and $600 \mathrm{r} / \mathrm{min}$. The data in the figures reveal that

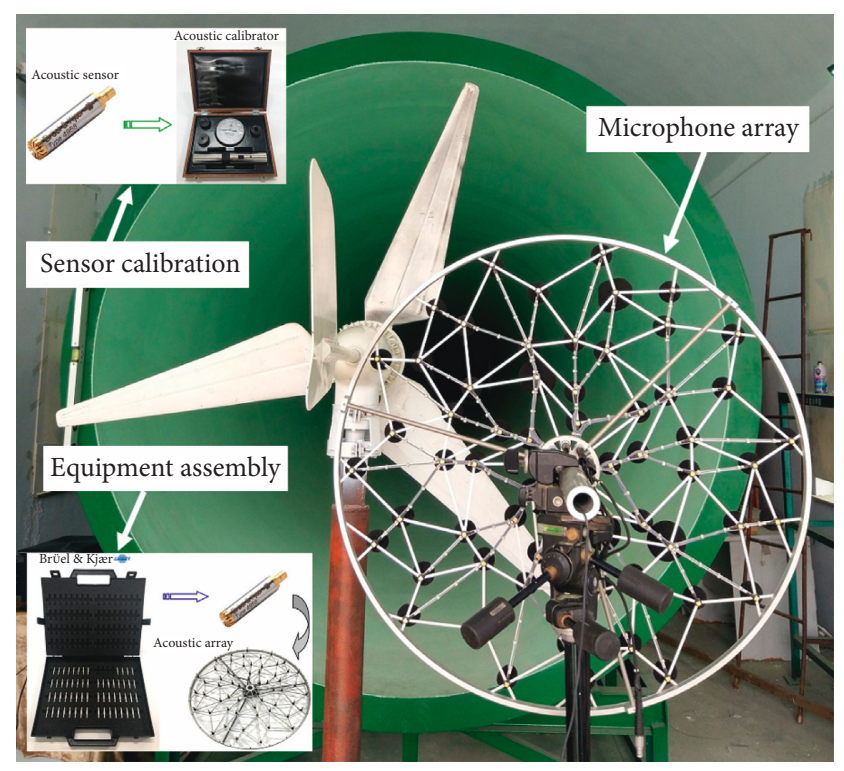

FIGURE 9: Installation example of test equipment.

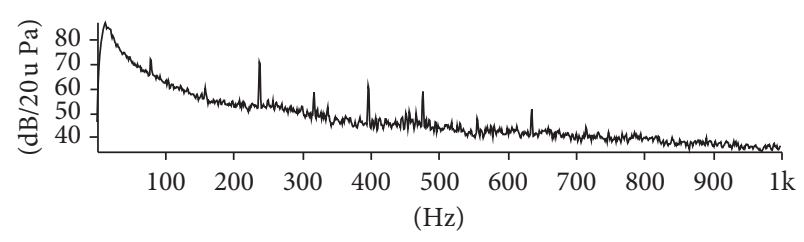

— Total (View 1)(1,1) (Real)\FFT analyzer

FIGURE 10: Background noise spectrum at a wind speed of $8 \mathrm{~m} / \mathrm{s}$.

blade aerodynamic noise is mainly composed of rotating fundamental frequency noise and its harmonic signals.

Meanwhile, the sound pressure levels for the fundamental frequency noise and its 2 nd-4th harmonic noises are found to be much higher than those of other noises. Consequently, the combined value of these four noise signals reflects, to a certain extent, the total value of the blade noise. Therefore, subsequent analyses mainly focused on the sound pressure levels of these signals.

Figure 12 shows the differences between the sound pressure levels of the original and modified blades at the same wind speed and blade rotational speed. Clearly, the sound pressure level of the modified blades was lower than that of the original blades, which indicates that airfoil concavity considerably decreased aerodynamic noise.

Meanwhile, the graphs in Figure 12 also show that the sound pressure levels increase with increasing blade rotation speed at constant wind speed. Similarly, the sound pressure levels increase with increasing wind speed at constant blade rotation speed.

To analyze how the noise reduction effect varies for different types of aerodynamic noises with equal blade rotation and wind speeds, for the same type of noise, we can express the reduction in the sound pressure level caused by airfoil concavity under identical working conditions as $\varphi_{i}$ using the following equation: 


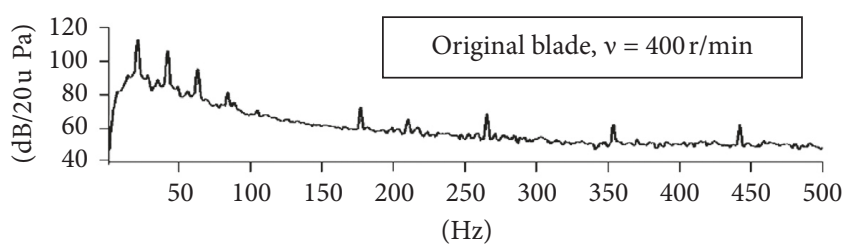

_ Total (View 1)(1, 1) (Real)\FFT analyzer

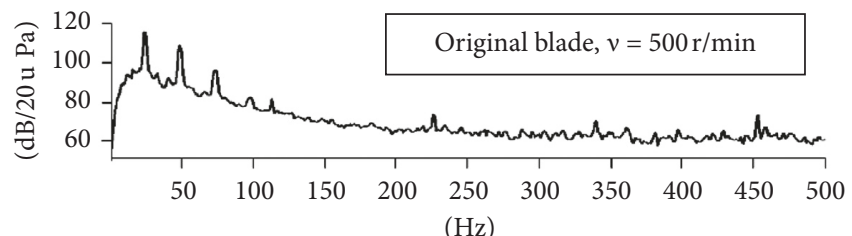

_ Total (View 1)(1, 1) (Real) \FFT analyzer

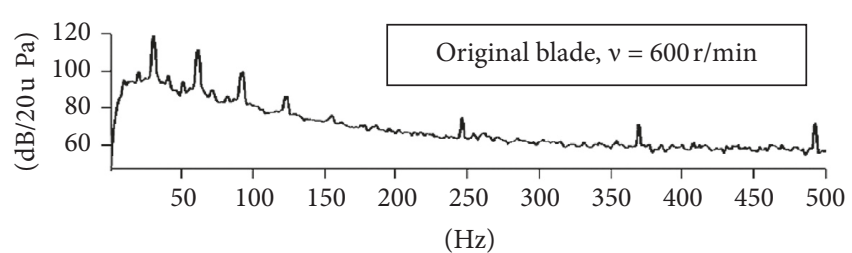

_ Total (View 1)(1, 1) (Real) \FFT analyzer

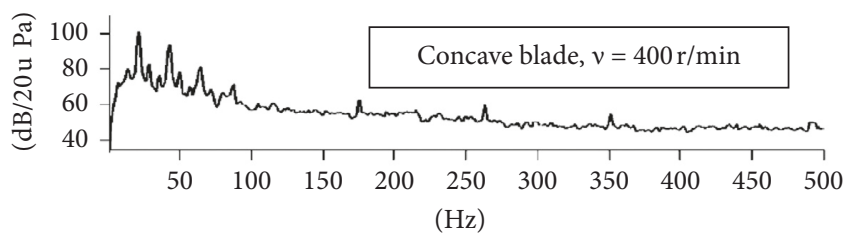

_ Total (View 1)(1, 1) (Real)\FFT analyzer

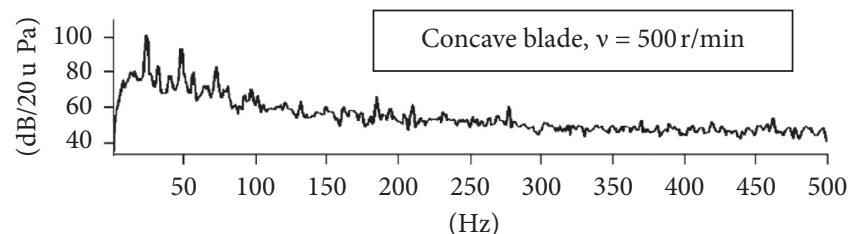

_ Total (View 1) $(1,1)$ (Real) \FFT analyzer

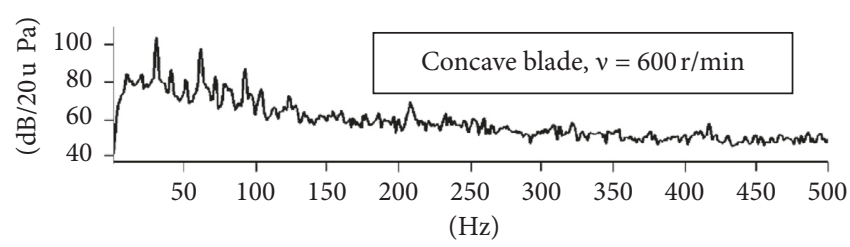

_ Total (View 1)(1, 1) (Real)\FFT analyzer

Figure 11: Noise spectra for original blade and concave blade.

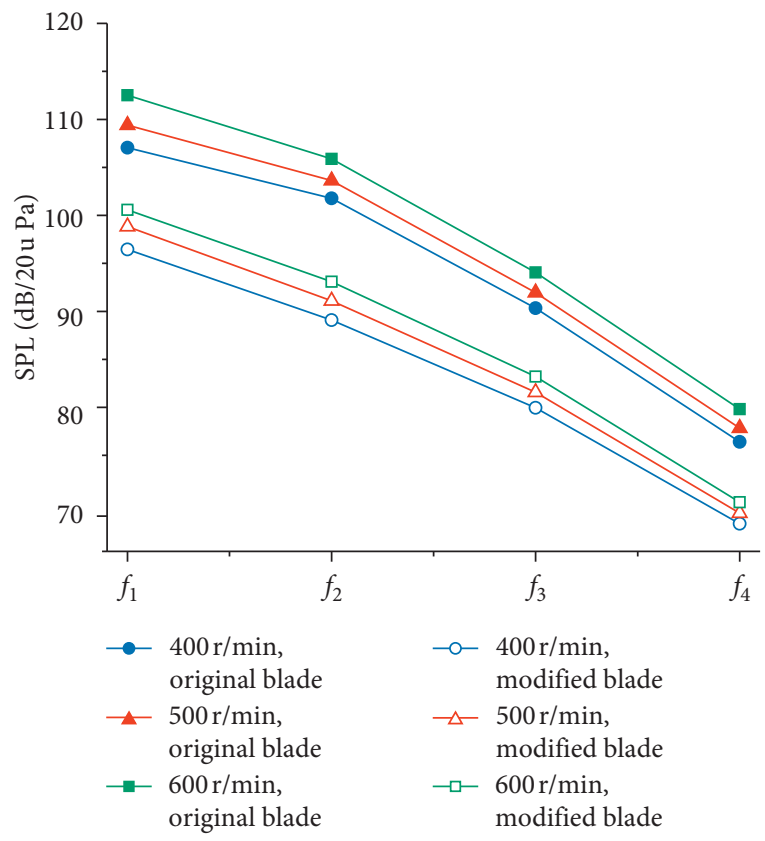

(a)

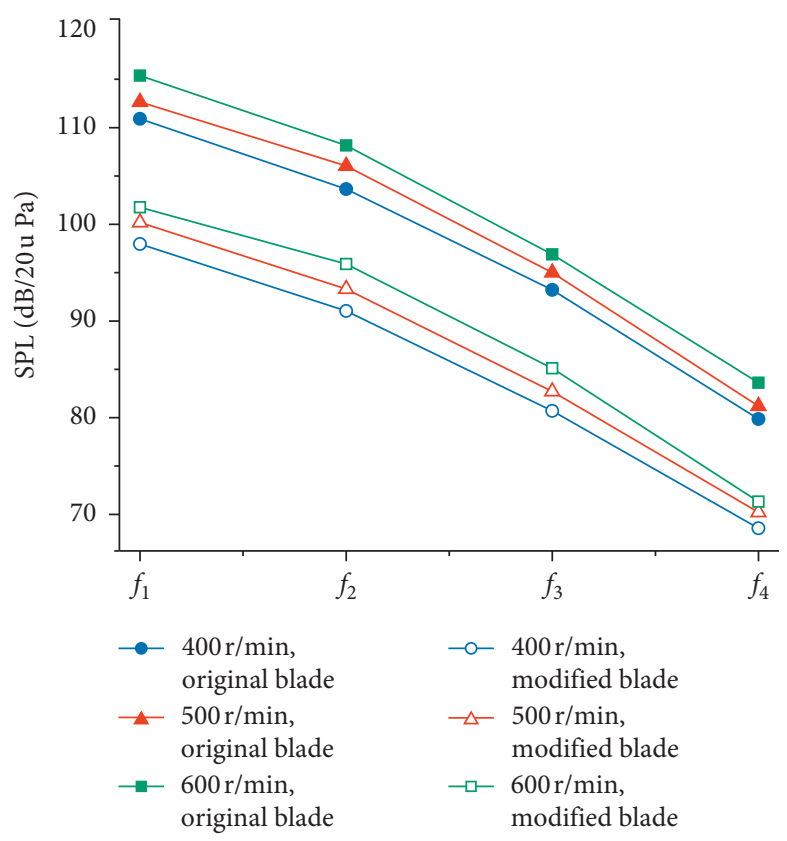

(b)

Figure 12: Continued. 


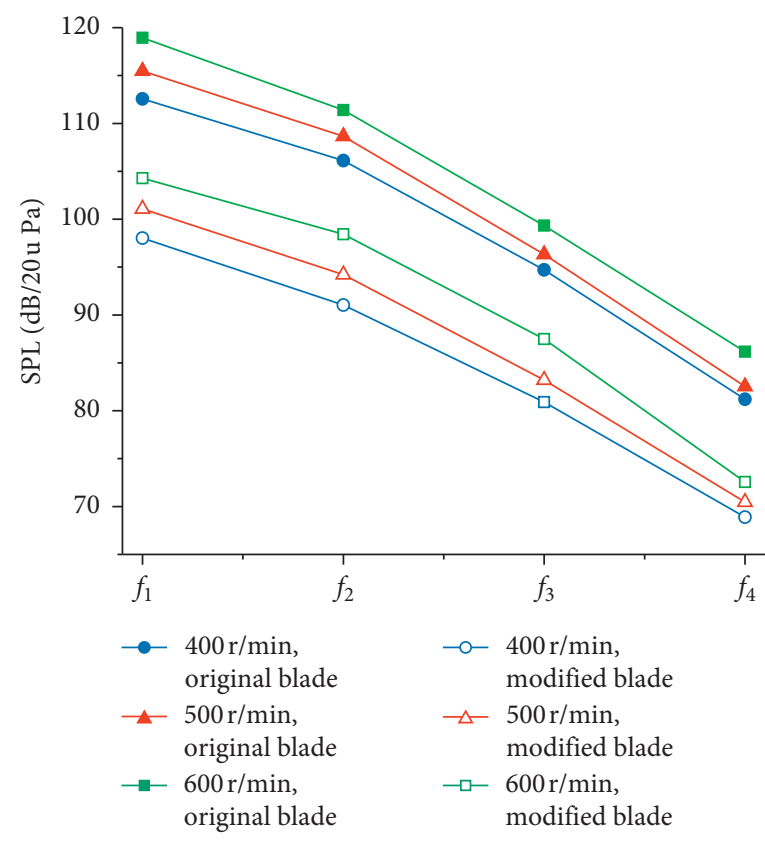

(c)

FIGURE 12: Differences between sound pressure levels of the original and modified blades. $v$ represents the wind speed; $f_{1}$ is the blade rotating fundamental frequency; $f_{2}, f_{3}$, and $f_{4}$ are two, three, and four times the value of $f_{1}$. (a) $v=6 \mathrm{~m} / \mathrm{s}$. (b) $v=7 \mathrm{~m} / \mathrm{s}$. (c) $v=8 \mathrm{~m} / \mathrm{s}$.

$$
\varphi_{i}=\mathrm{SPL}_{\text {original }, i}-\mathrm{SPL}_{\text {modified }, i}
$$

where $(i=1,2,3,4), 1,2,3$, and 4 represent the fundamental frequency and the second, third, and fourth harmonics, respectively. To analyze the sensitivity of the noise reduction to airfoil concavity, we can define the parameter $\psi$ with the following equation under identical working conditions:

$$
\psi_{i}=\frac{\varphi_{i}}{\mathrm{SPL}_{\text {original }, i}} \times 100 \%
$$

The corresponding results are demonstrated in Figure 13, which reveals that at a wind speed of $6 \mathrm{~m} / \mathrm{s}$, airfoil concavity remarkably reduced the second harmonic noise. At a blade rotation speed of $400 \mathrm{r} / \mathrm{min}$, the sound reduction effect of concavity successively decreased with the increasing sound frequency. However, at rotational speeds of 500 and $600 \mathrm{r} / \mathrm{min}$, the fourth harmonic noise was more significantly reduced by airfoil concavity than the third harmonic noise.

In addition, at wind speeds of 7 and $8 \mathrm{~m} / \mathrm{s}$, the noise reduction effect of airfoil concavity on harmonic noise was more significant. Meanwhile, the noise reduction effect significantly increased with the increasing noise frequency. The above analysis indicates that airfoil concavity could improve the acoustic performance of rotor blades.

4.4. Analysis of Test Error and Data Reliability. The acoustic signals were measured by using the 60-channel circular acoustic array developed by B\&K Company of Denmark, whose measurement error is less than $1 \mathrm{~dB}$. It is not sufficient to affect the reliability of the above analysis.

\section{Effects of Airfoil Concavity on Blade Structural Safety}

Natural frequency and structural robustness are important parameters that indicate the structural safety of wind turbine blades. However, airfoil concavity changes the structural characteristics and mass distribution of the blade, which in turn inevitably affect its natural frequency and structural robustness. These new characteristics will also affect the feasibility of airfoil concavity technology.

5.1. Test System and Methods. This test was also completed using the PULSE device. A flow chart of the test is shown in Figure 14.

Eight unidirectional acceleration sensors were evenly arranged along each edge of the blade of the wind wheel. The transient excitation method was applied with single-point excitation and multipoint response. The mathematical model of the wind wheel is shown in Figure 15. The data collected from different sensors agreed well, as shown in Figure 16, indicating the high precision of the test.

5.2. Test Results and Analysis. The natural frequencies and corresponding damping ratios of the first- and second-order vibrations for the original and modified blades are listed in Table 1. 


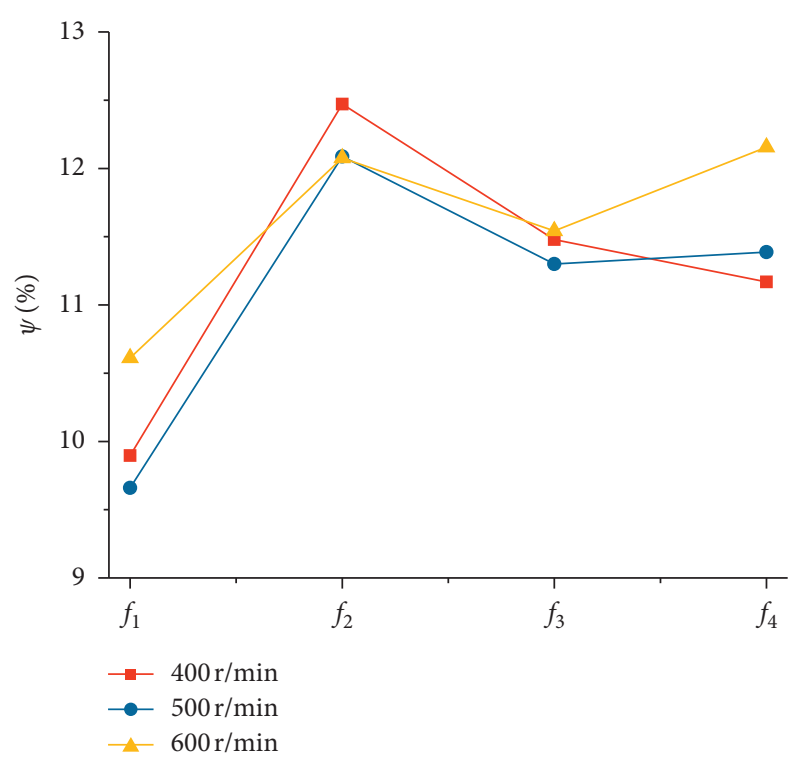

(a)

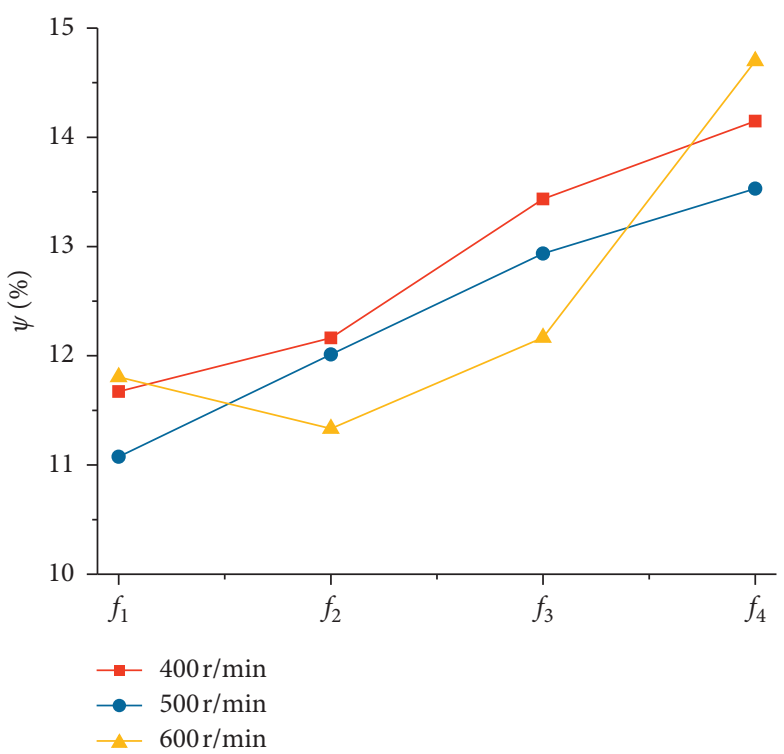

(b)

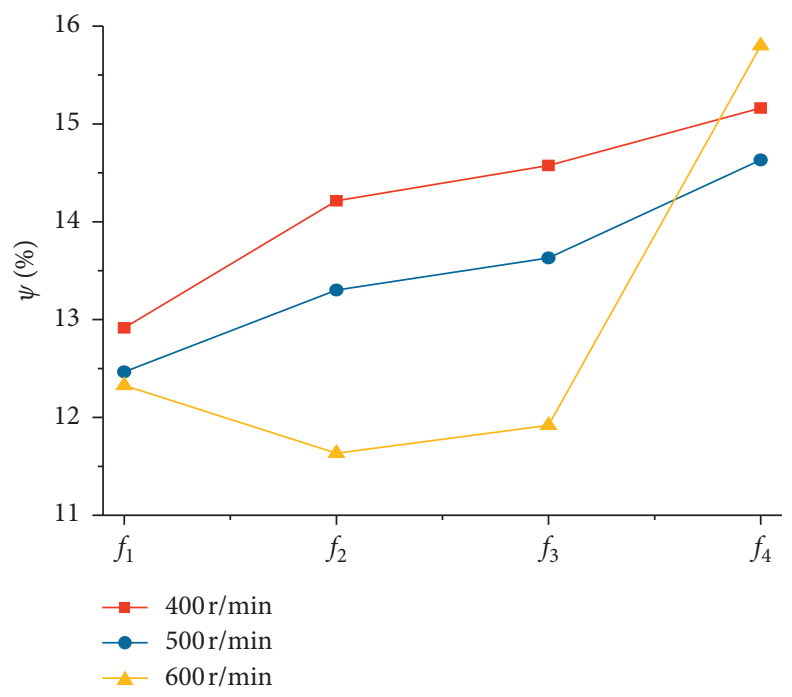

(c)

FIGURE 13: Variations in $\psi$ at different frequencies. (a) $v=6 \mathrm{~m} / \mathrm{s}$. (b) $v=7 \mathrm{~m} / \mathrm{s}$. (c) $v=8 \mathrm{~m} / \mathrm{s}$.

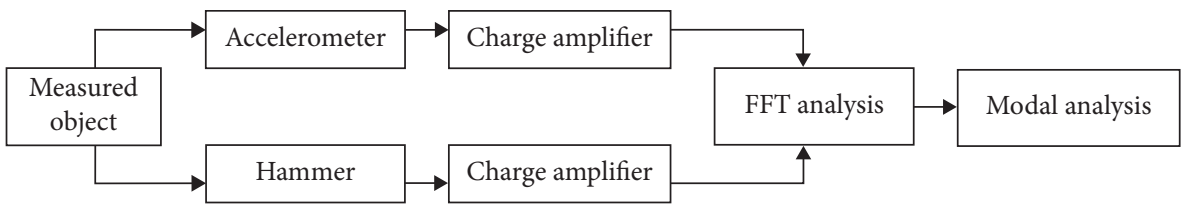

FIGURE 14: Test flow chart.

As shown in Table 1, airfoil concavity can increase the natural frequencies of the blade's first- and second-order vibrations to some extent. However, the effects of airfoil concavity on the damping ratios of the first- and secondorder vibrations are quite significant, with increments of 81.6 and $54.8 \%$, respectively. Moreover, stiffness is the most important parameter that reflects blade structural robustness. Therefore, we analyzed the effects induced by airfoil concavity using the following equations:

$$
\begin{aligned}
& f=\sqrt{\frac{k}{m}} \cdot \sqrt{1-\zeta^{2}}, \\
& k=m \frac{f^{2}}{1-\zeta^{2}},
\end{aligned}
$$

where $f$ is the natural frequency, $k$ is the stiffness, $m$ is the mass, and $\zeta$ is the damping ratio. 


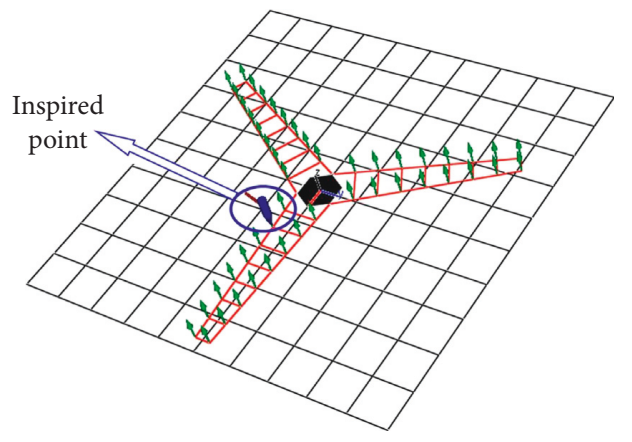

Figure 15: Mathematical model of the wind wheel.

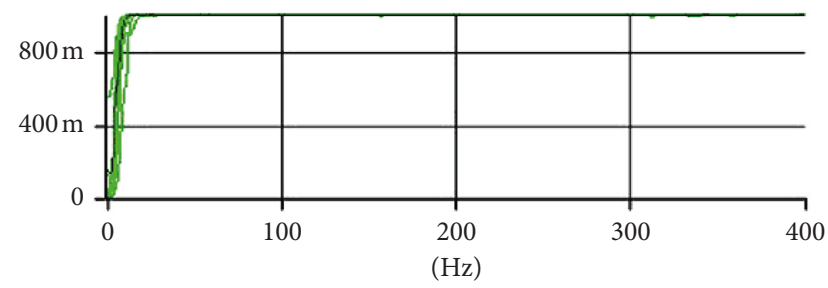

FIGURE 16: Coherence of modal test data.

TABle 1: Modal test results.

\begin{tabular}{lcccc}
\hline Blade & $f_{1}(\mathrm{~Hz})$ & $f_{2}(\mathrm{~Hz})$ & $\zeta_{1}(\%)$ & $\zeta_{2}(\%)$ \\
\hline Original & 27.4 & 60.7 & 7.6 & 4.2 \\
Modified & 28.3 & 62.4 & 13.8 & 6.5 \\
$\varphi(\%)$ & 3.3 & 2.8 & 81.6 & 54.8 \\
\hline
\end{tabular}

$f_{1}$ and $f_{2}$ represent the natural frequencies of the first- and second-order vibrations of the blade, $\zeta_{1}$ and $\zeta_{2}$ represent the corresponding damping ratios, and $\varphi$ represents the relative increase in the same parameter.

Applying concavity to the airfoil reduced the blade mass by $8 \mathrm{~g}$ (approximately $1 \%$ of the total mass); meanwhile, the frequencies increased slightly, as shown in Table 1. Owing to the significant increase in the damping ratios, the stiffness values of the blade's first- and second-order vibrations increased by 7.0 and $4.9 \%$, respectively, which indicates that airfoil concavity significantly increases the blade stiffness.

According to blade structure design theory, the 1st-order vibration parameters of a blade are key parameter. The actual excitation frequencies during blade rotation are often lower than the natural frequency of the first-order vibration. Therefore, increases in the natural frequencies of a blade caused by airfoil concavity can reduce the probability of blade resonance, and simultaneously, the significant increase in blade stiffness caused by airfoil concavity can effectively enhance the structural safety of the blade.

5.3. Analysis of Test Error and Data Reliability. The measurement error of vibration frequency caused by the PULSE device is less than $0.125 \mathrm{~Hz}$. According to the data in Table 1, the minimum difference between vibration frequencies is $0.9 \mathrm{~Hz}$, so the measurement error cannot affect the reliability of the above conclusions.

On the contrary, the measurement error of the vibration acceleration values introduced by the PULSE device does not exceed $0.3 \%$, so it also has no influence on the reliability of the relevant conclusions.

\section{Conclusions}

Airfoil concavity is an important method for preventing or postponing flow separation in airfoil design. However, whether airfoil concavity is suitable to improve the aerodynamic performance of wind turbine blades remains unknown, which is an important scientific issue.

In this study, we performed an exploratory experimental study with small horizontal-axis wind turbine blades. The results indicated that it can improve blade aerodynamic performance by $3-15 \%$ through applying appropriate airfoil concavity at the suction surface (where flow separation easily occurs) of the blade.

Meanwhile, the sound pressure level of the blade aerodynamic noise was significantly reduced by $9.6-15.8 \%$, and its stiffness of the first- and second-order vibrations can effectively be increased by 7.0 and $4.9 \%$.

Overall, airfoil concavity can be applied to improve the aerodynamic performance, aerodynamic noise, and structural robustness of small horizontal-axis wind turbine blades. Therefore, it has great feasibility to optimize the overall performance of small horizontal-axis wind turbine blades.

However, whether the method is equally applicable to the optimization of large-scale wind turbine performance remains unknown, which is a direction of the author's future research work.

\section{Data Availability}

All the data used to support the findings of this study are available from the corresponding author upon request.

\section{Conflicts of Interest}

The authors declare that they have no conflicts of interest.

\section{Acknowledgments}

This study was supported by the Foundation of Key Laboratory of Wind Energy and Solar Energy Technology, Ministry of Education of China (2017ZD01) and the Program for Young Talents of Science and Technology in Universities of Inner Mongolia Autonomous Region of China (grant no. NJYT-17-B24).

\section{References}

[1] W. Weber, "Design and development of voith's wind turbine," Voith Research and Construction, vol. 29, pp. 1-6, 1982.

[2] J. L. Tangler and D. M. Somers, "NREL airfoil families for HAWTs," NASA STI/recon Technical Report NREL/TP-4427109, USDOE, Washington, DC, USA, 1995.

[3] W. A. Timmer and R. P. J. O. M. Van Rooij, "Summary of the delft university wind turbine dedicated airfoils," Journal of Solar Energy Engineering, vol. 125, no. 4, pp. 488-496, 2003.

[4] A. Björk, Coordinates and Calculations for the FFA-W1-xxx, FFA-W2-xxx and FFA-W3-xxx Series of Airfoils for Horizontal 
Axis Wind Turbines, Aeronautical Research Institute of Sweden, Stockholm, Sweden, 1990.

[5] P. Fuglsang and C. Bak, "Development of the Risø wind turbine airfoils," Wind Energy, vol. 7, no. 2, pp. 145-162, 2004.

[6] M. Birajdar, S. Kale, and S. N. Sapali, Effects of Design Parameters on Aerodynamic Performance of New Profile Small Wind Turbine Blades, IMECE2015, Houston, TX, USA, 2016.

[7] R. K. Singh and M. R. Ahmed, "Blade design and performance testing of a small wind turbine rotor for low wind speed applications," Renewable Energy, vol. 50, pp. 812-819, 2013.

[8] H. Shah, S. Mathew, and C. M. Lim, "A novel low Reynolds number airfoil design for small horizontal axis wind turbines," Wind Engineering, vol. 38, no. 4, pp. 377-391, 2014.

[9] A. R. Elbakheit, "Factors enhancing aerofoil wings for wind energy harnessing in buildings," Building Services Engineering Research and Technology, vol. 35, no. 4, pp. 417-437, 2014.

[10] M. Menon, F. Ponta, X. Sun, and Q. Dai, "Aerodynamic analysis of flow-control devices for wind turbine applications based on the trailing-edge slotted-flap concept," Journal of Aerospace Engineering, vol. 29, no. 5, article 04016037, 2016.

[11] Y. Liu, C. Yang, and X. Song, "An airfoil parameterization method for the representation and optimization of wind turbine special airfoil," Journal of Thermal Science, vol. 24, no. 2, pp. 99-108, 2015.

[12] J. C. C. Henriques, F. Marques da Silva, A. I. Estanqueiro, and L. M. C. Gato, "Design of a new urban wind turbine airfoil using a pressure-load inverse method," Renewable Energy, vol. 34, no. 12, pp. 2728-2734, 2009.

[13] J. L. Dowler and S. Schmitz, "A solution-based stall delay model for horizontal-axis wind turbines," Wind Energy, vol. 18, no. 10, pp. 1793-1813, 2015.

[14] J. Chen, Q. Wang, S. Zhang, P. Eecen, and F. Grasso, "A new direct design method of wind turbine airfoils and wind tunnel experiment," Applied Mathematical Modelling, vol. 40, no. 3, pp. 2002-2014, 2016.

[15] C. Brehm, A. Gross, and H. F. Fasel, "Open-loop flow-control investigation for airfoils at low reynolds numbers," AIAA Journal, vol. 51, no. 8, pp. 1843-1860, 2013.

[16] C. Chen, R. Seele, and I. Wygnanski, "Flow control on a thick airfoil using suction compared to blowing," AIAA Journal, vol. 51, no. 6, pp. 1462-1472, 2013.

[17] R. Azim, M. M. Hasan, and M. Ali, "Numerical investigation on the delay of boundary layer separation by suction for NACA 4412," Procedia Engineering, vol. 105, pp. 329-334, 2015.

[18] G. M. McNerney, C. P. Van Dam, and D. T. Yen-Nakafuji, "Blade-wake interaction noise for turbines with downwind rotors," Journal of Solar Energy Engineering, vol. 125, no. 4, pp. 497-505, 2003.

[19] J. Cheng, J. Chen, W. Shen et al., "Optimization design of airfoil profiles based on the noise of wind turbines," Acta Energiae Solaris Sinica, vol. 33, no. 4, pp. 558-563, 2012.

[20] J. Cheng, W. Zhu, A. Fischer et al., "Design and validation of the high performance and low noise CQU-DTU-LN1 airfoils," Wind Energy, vol. 17, no. 12, pp. 1817-1833, 2014.

[21] S. S. Rodrigues and A. C. Marta, "On addressing wind turbine noise with after-market shape blade add-ons," Renewable Energy, vol. 140, pp. 602-614, 2019.

[22] A. C. Benim, M. Diederich, F. Gül, P. Oclon, and J. Taler, "Computational and experimental investigation of the aerodynamics and aeroacoustics of a small wind turbine with quasi-3D optimization," Energy Conversion and Management, vol. 177, pp. 143-149, 2018.
[23] S. Sanaye and A. Hassanzadeh, "Multi-objective optimization of airfoil shape for efficiency improvement and noise reduction in small wind turbines," Journal of Renewable and Sustainable Energy, vol. 6, no. 5, article 053105, 2014.

[24] F. Bertagnolio, H. A. Madsen, and C. Bak, "Trailing edge noise model validation and application to airfoil optimization," Journal of Solar Energy Engineering-Transactions of the ASME, vol. 132, no. 3, 2010.

[25] S. S. Rodrigues and A. C. Marta, "On addressing noise constraints in the design of wind turbine blades," Structural and Multidisciplinary Optimization, vol. 50, no. 3, pp. 489503, 2014.

[26] P. Pourazarm, L. Caracoglia, M. Lackner, and Y. ModarresSadeghi, "Stochastic analysis of flow-induced dynamic instabilities of wind turbine blades," Journal of Wind Engineering and Industrial Aerodynamics, vol. 137, pp. 37-45, 2015.

[27] P. Pourazarm, Y. Modarres-Sadeghi, and M. Lackner, "A parametric study of coupled-mode flutter for MW-size wind turbine blades," Wind Energy, vol. 19, no. 3, pp. 497-514, 2016.

[28] M. M. A. Hafeez and A. A. El-Badawy, "Flutter limit investigation for a horizontal axis wind turbine blade," Journal of Vibration and Acoustics, vol. 140, no. 4, article 041014, 2018.

[29] J. Howison, J. Thomas, and K. Ekici, "Aeroelastic analysis of a wind turbine blade using the harmonic balance method," Wind Energy, vol. 21, no. 4, pp. 226-241, 2018.

[30] B. Chen, Z. Zhang, X. Hua, S. R. K. Nielsen, and B. Basu, "Enhancement of flutter stability in wind turbines with a new type of passive damper of torsional rotation of blades," Journal of Wind Engineering and Industrial Aerodynamics, vol. 173, pp. 171-179, 2018.

[31] E. Verstraelen, G. Habib, G. Kerschen, and G. Dimitriadis, "Experimental passive flutter suppression using a linear tuned vibration absorber," AIAA Journal, vol. 55, no. 5, pp. 17071722, 2017. 


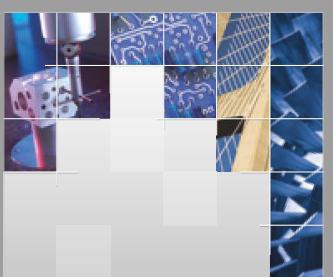

\section{Enfincering}
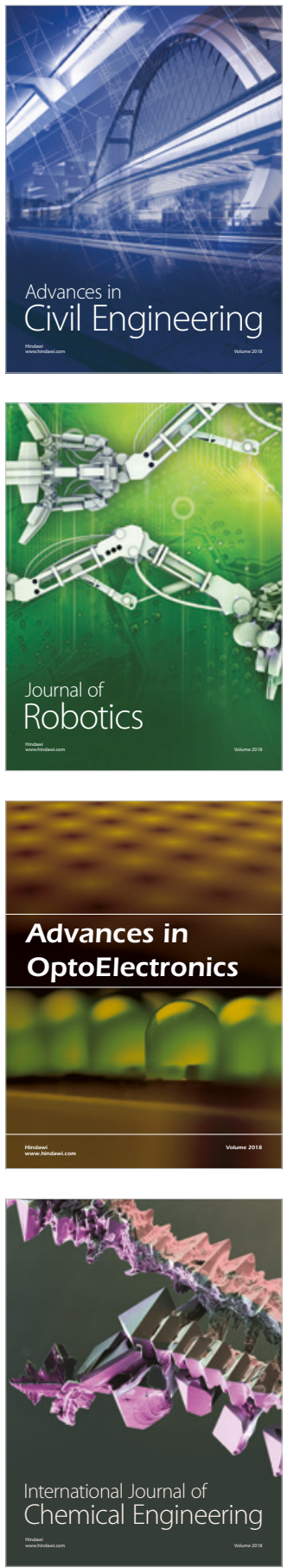

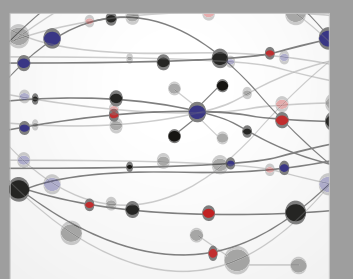

\section{Rotating \\ Machinery}

The Scientific World Journal

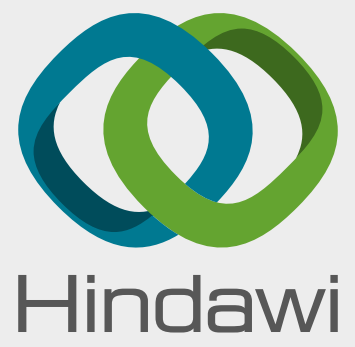

Submit your manuscripts at

www.hindawi.com
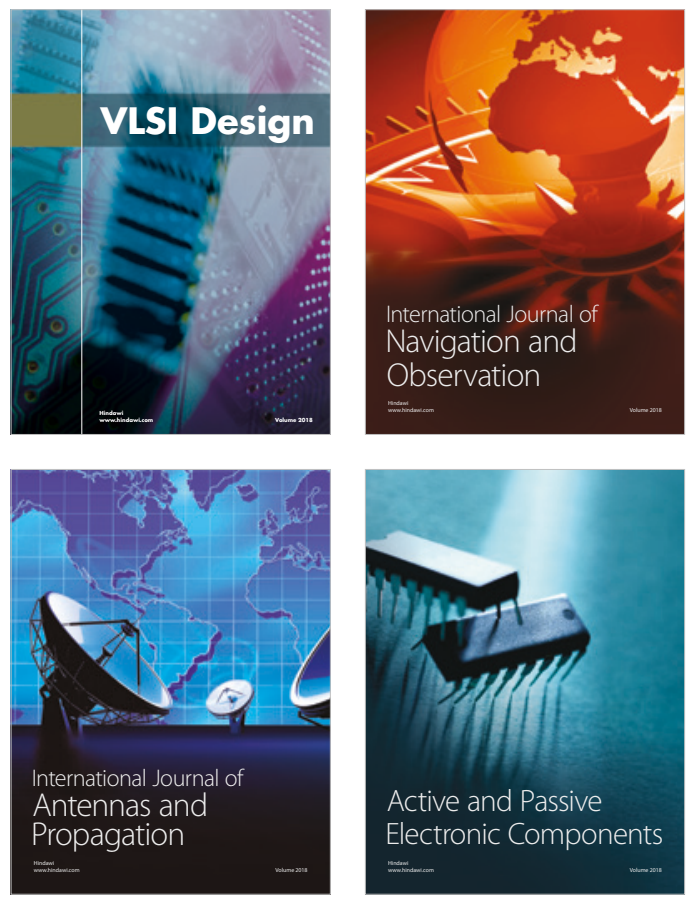
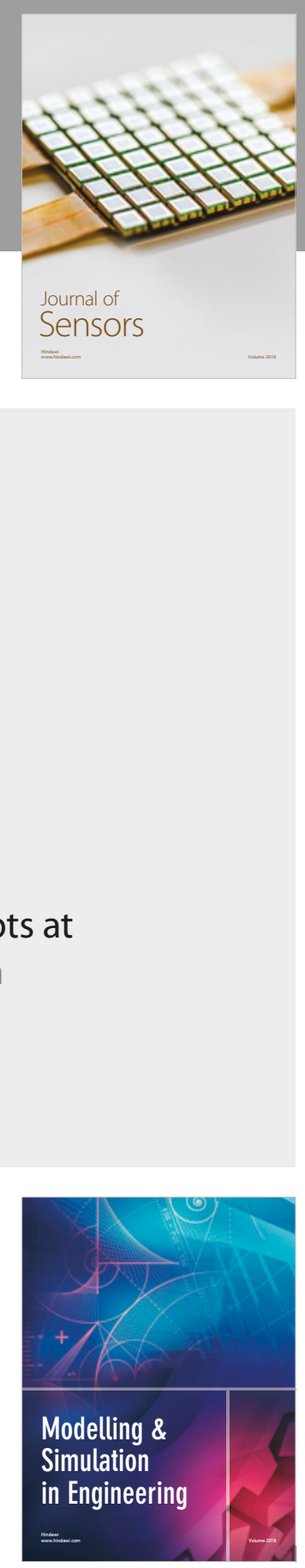

\section{Advances \\ Multimedia}
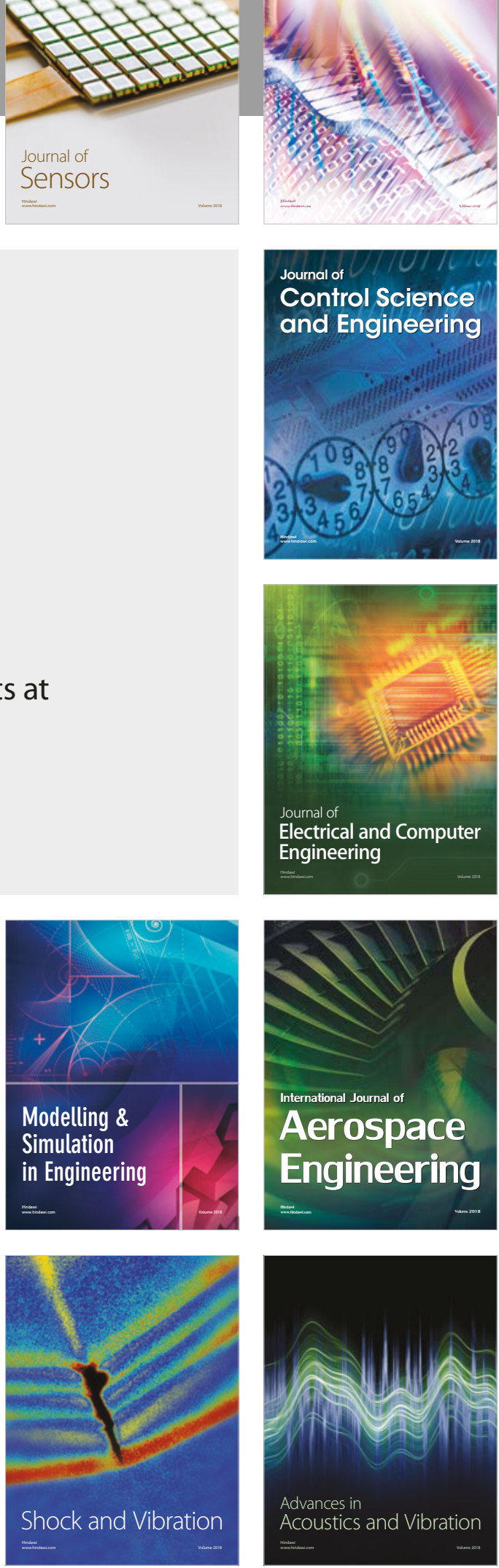